\title{
IMPLEMENTASI KEBIJAKAN DESA BUDAYA DALAM MELESTARIKAN BUDAYA LOKAL DI DESA SENDANGMULYO, MINGGIR, SLEMAN.
}

\author{
T. Prasetyo Hadi Atmoko \\ Dosen Akademi Pariwisata Yogyakarta \\ prasplg@gmail.com
}

\begin{abstract}
Local cultural values in cultural interaction cause people tend to ignore the values of local culture so that requires a policy in preserving local culture in the village Sendangmulyo, Minggir, Sleman. The purpose of this study is to know the potential of Sendangmulyo village and how the implementation of village culture policy in preserving local culture in Sendangmulyo village, Minggir, Sleman. This research method using descriptive qualitative research method. Based on research, Sendangmulyo village has cultural potential such as tabuh gamelan, dance art, Jathilan and Encling, Thek-Thek, Gejog Lesung, kethoprak, craft and culinary, and merti desa. Implementation of cultural village policy based on the assessment of the Culture Department of Yogyakarta, Sendangmulyo is in the category of advanced cultural village. The power factor of Sendangmulyo village is the cultural potential and the support of the community. Weakness of less skilled human resources, institutional lack of understanding of its function, as well as inadequate facilities become weaknesses, as well as understanding the culture and involvement of young people who are still less a threat factor. Opportunities that can be developed that Sendangmulyo village can be a cultural destination. In overcoming the weaknesses of human resources, institutions and facilities and infrastructure in Sendangmulyo village, the village government with the support of the Provincial Cultural Office of Yogyakarta Specialized by increasing the motivation, knowledge and participation of the community through trainings, improving village management institutions through increased management, village culture and provide funding to hold a cultural title.
\end{abstract}

Keywords: Policy, cultural village, preserve

\section{PENDAHULUAN}

Setiap warganegara Indonesia berhak menjunjung tinggi kebudayaannya. Kebudayaan nasional mengacu pada nilai - nilai unggulan dari budaya-budaya lokal yang menjadi warisan budaya bangsa Indonesia (culture heritage). Kebudayaan akan sangat dipengaruhi oleh perkembangan teknologi informasi dan komunikasi. Menurut Koentjaraningrat (2009:146) dalam setiap budaya terdapat di dalamnya unsur-unsur yang juga dimiliki oleh berbagai budaya lain. Generasi muda sebagai pemangku kebudayaan di masa yang akan datang dituntut untuk memiliki kemampuan menjaga keragaman kebudayaan Indonesia. Pelestarian budaya sebagai pelestarian tradisi adalah upaya perlindungan, pengembangan dan pemanfaatan suatu kebiasaan dari kelompok masyarakat pendukung kebudaya-an yang penyebaran dan pewarisannya berlangsung secara turun temurun (Peraturan Menteri Pendidikan dan kebudayaan Republik Indonesia Nomor 10 
tahun 2014). Kebudayaan merupakan salah satu sumber daya yang sangat penting dalam pembangu-nan kepariwisataan. Pariwisata dan budaya saling berkaitan. Budaya merupakan daya tarik wisata dengan mempromosikan karakteristik budaya dari destinasi, sehingga wisatawan melakukan perjalanan wisatanya. Tujuan dari pariwisata budaya adalah memahami makna suatu budaya, bukan sekedar mendeskripsikan suatu budaya. Dalam upaya pelestarian dan pengembangan kebudayaan tentu memiliki berbagai kendala. Nilai-nilai kearifan lokal dan kebudayaan suku bangsa dengan masuknya unsur-unsur budaya asing menyebabkan masyarakat mengabaikan nilai - nilai budaya lokal, nilai - nilai kearifan lokal seperti gotong royong, musyawarah mufakat, dan tenggang rasa sulit ditemukan lagi dalam kehidupan bermasyarakat saat ini. Menurut Mubah (2011) budaya lokal perlu memperkuat daya tahannya dalam menghadapi globalisasi budaya asing. Beberapa strategi yang dapat dilakukan untuk meningkatkan daya tahan budaya lokal, antara lain (1) pembangunan jati diri bangsa, (2) pemahaman falsafah budaya, (3) penerbitan peraturan daerah, dan (4) pemanfaatan teknologi informasi.

Pelestarian budaya lokal melalui desa budaya di desa Sendangmulyo memiliki kendala baik sumberdaya manusia, kelembagaan dan sarana pra-sarananya. Untuk itu perlu menggali dan mengembangkan potensi dan perlu adanya kebijakan pemerintah dalam pelestarian budaya agar budaya lokal tidak luntur bahkan punah. Oleh karena itu penelitian ini brupaya menjelaskan: (1) potensi apa saja yang ada di Desa Sendangmulyo, Minggir, Sleman? (2) bagaimana implementasi kebijakan Desa Budaya dalam melestarikan budaya lokal di desa Sendangmulyo, Minggir, Sleman?, yang hasilnya diharapkan dapat digunakan sebagi strategi desa budaya dalam melestarikan budaya lokal supaya tidak punah. Sedangkan manfaat praktis dari penelitian ini adalah untuk meningkatkan pemahaman budaya lokal di kalangan generasi muda supaya tidak luntur karena masuknya budaya asing.

\section{LITERATURE REVIEW \\ Implementasi}

Implementasi diartikan pelaksanaan atau penerapan. Majone dan Wildavsky dalam Nurdin dan Usman (2002), mengemukakan implementasi sebagai evaluasi. Browne dan Wildavsky dalam Nurdin dan Usman (2002) mengemukakan bahwa implementasi adalah perluasan aktivitas yang saling menyesuaikan. Pengertian implementasi sebagai aktivitas yang saling menyesuaikan juga dikemukakan oleh Mclaughin dalam Nurdin dan Usman (2002). Adapun Schubert dalam Nurdin dan Usman (2002) mengemukakan bahwa implementasi adalah sistem rekayasa. Pengertianpengertian di atas memperlihatkan bahwa kata implementasi mengacu pada aktivitas, adanya aksi, tindakan, atau mekanisme suatu sistem. Ungkapan mekanisme mengandung arti bahwa implementasi bukan sekadar aktivitas, tetapi suatu kegiatan yang terencana dan dilakukan secara sungguh-sungguh berdasarkan acuan norma tertentu untuk mencapai tujuan kegiatan.

\section{Kebijakan}

Menurut Mustopadidjaja dalam Tahir (2014) menjelaskan bahwa istilah kebijakan lazim digunakan dalam kaitannya atau kegiatan pemerintah, serta perilaku negara pada umumnya dan kebijakan tersebut dituangkan dalam berbagai bentuk 
peraturan. Sedangkan menurut Anderson dalam Tahir (2014) kebijakan adalah suatu tindakan yang mempunyai tujuan yang dilakukan seseorang pelaku atau sejumlah pelaku untuk memecahkan suatu masalah. Jadi dapat disimpulkan bahwa kebijakan sebagai keputusan untuk mencapai tujuan tertentu.

\section{Desa Budaya}

Desa Budaya adalah wahana sekelompok manusia yang melakukan aktivitas budaya yang mengekspresikan sistem kepercayaan (religi), sistem kesenian, sistem mata pencaharian, sistem teknologi, sistem komunikasi, sistem sosial, dan sistem lingkungan, tata ruang, dan arsitektur dengan mengaktualisasikan kekayaan potensi dan mengkonservasinya dengan saksama atas kekayaan budaya yang dimilikinya, terutama yang tampak pada adat dan tradisi, seni pertunjukan, kerajinan, dan tata ruang dan arsitektural. Tujuan dari Desa Budaya adalah melestarikan dan mengembangkan potensi Adat tradisi, Kesenian, Kerajinan, arsitektur dan tata ruang agar menumbuhkan jatidiri, pembentuk citra desa sebagai salah satu penyusun untuk mencapai visi DIY sebagai Pusat Budaya, serta mampu meningkatkan kesejahteraan masyarakat (Dinas Kebudaya-an Propinsi DIY, 2016). Strategi pengemba-ngan desa budaya direkomendasikan dalam gambar 1 .

\section{Kebudayaan}

Kebudayaan berasal dari kata "budaya". Budaya diserap dari bahasa Sanskerta "buddhayah" yaitu bentuk jamak dari "buddhi" yang berarti budi atau akal. Dengan demikian kebudayaan dapat diartikan hal-hal yang bersangkutan dengan akal. Dalam bahasa sehari-hari kebudayaan dibatasi hanya pada hal-hal yang indah seperti candi, tarian-tarian, seni rupa, seni suara, kesusastraan dan filsafat saja. Sedang-kan dalam ilmu antropologi jauh lebih luas sifat dan ruang lingkupnya. Menurut ilmu antropologi kebudayaan adalah keseluruhan sistem gagasan, tindakan, dan hasil karya manusia dalam kehidupan masyarakat yang dijadikan milik diri manusia dengan belajar (Koentjaraningrat, 2009). Menurut Sutrisno (2009), kebudayaan adalah proses manusia bersama subyek lain untuk menata hidup bersama dengan acuan nilai-nilai kemanusiaan, pencerahan, peradaban yang dihayati dalam proses perubahan sikap mental, perilaku dan cara pikir serta pandangan mengenai hidup.

\begin{tabular}{|l|}
\hline \multicolumn{2}{|c|}{ SUMBER DAYA MANUSIA } \\
Meningkatkan motivasi, pengetahuan, \\
partisipasi, dan regenerasi warga \\
masyarakat desa budaya untuk mengak- \\
tualisasikan dan mengkonservasi potensi \\
budaya \\
\hline \multicolumn{1}{c|}{ KELEMBAGAAN } \\
Meningkatkan lembaga pengelola desa \\
budaya melalui upaya pengorganisasian \\
yang baik, meningkatkan manajemen dan \\
pengembangan jaringan untuk mengak- \\
tualisasikan dan mengkonservasi potensi \\
budaya PRASARANA \\
\hline $\begin{array}{l}\text { Meningkatkan prasarana pendukung desa } \\
\text { melalui upaya pendanaan, } \\
\text { peningkatan peralatan, peningkatan } \\
\text { pemanfaatan informasi, dan perluasan } \\
\text { akses untuk mengaktualisasikan dan } \\
\text { mengkonservasi potensi budaya }\end{array}$ \\
Gambar 1. Strategi Pengembangan Desa \\
Budaya
\end{tabular}

Pengertian kebudayaan juga termasuk tradisi, tradisi merupakan pewarisan atau penerusan norma-norma, adat istiadat, harta. Manusia lah yang membuat sesuatu 
dengan tradisi itu, ia menolaknya, menerimanya atau mengubahnya. Itulah sebabnya mengapa kebudayaan merupakan cerita tentang perubahan (Peursen, 2009). Menurut Koentjaraningrat (2009) Wujud kebudayaan dibagi menjadi 3, yaitu:

a. Suatu kompleks ide, gagasan, nilai, norma, peraturan.

b. Suatu kompleks aktivitas serta tindakan berpola dari manusia dalam masyarakat.

c. Suatu benda-benda hasil karya manusia.

\section{METODE PENELITIAN}

Penelitian ini lebih ditekankan pada pendekatan kualitatif. Menurut Hendriansyah (2010:9) penelitian kualitatif adalah suatu penelitian ilmiah yang bertujuan memahami suatu fenomena dalam konteks sosial secara alamiah dengan mengedepankan proses interaksi komunikasi yang mendalam antara peneliti dengan fenomena yang diteliti. pendekatan ini lebih mengandalkan kekuatan pengamatan pancaindera untuk merefleksi fenomena budaya. Pendekatan kualitatif lebih kepada pertimbangan pancaindera secara akurat untuk melihat kebudayaan yang cenderung berubah-ubah seiring perubahan zaman. Dalam penelitian kualitatif peneliti cenderung sebagai pengumpul data, mengikuti asumsi kultural, dan mengikuti data sehingga penelitian kualitatif budaya lebih fleksibel.

Pelestarian budaya memerlukan sinergi Pemerintah Daerah dan Pengelola Desa Budaya dalam melaksanakan Pelestarian kebudayaan meliputi:

1. Aktor pelaksana

2. Program

3. Sarana dan prasarana.

Penguatan peran desa budaya membutuhkan dukungan aktor-aktor pelaksana.
Aktor-aktor pelaksana tersebut adalah pelaksana teknis dan non-teknis dalam melaksanakan pelestarian kebudayaan, yang dalam hal ini adalah Dinas Kebudayaan, Perangkat Desa Sendangmulyo, Pengelola desa budaya, dan masyarakat desa Sendangmulyo. Sinergi di antara aktor-aktor pelaksana ini sangat penting untuk menyelaraskan pelaksana program-program pelestarian kebudayaan lokal. Sinergi aktor pelaksana pelestari budaya lokal dapat dilihat dalam gambar 2 .

\section{HASIL PENELITIAN DAN PEMBAHASAN}

\section{Hasil Penelitian}

Berdasarkan SK Gubernur yang diserahkan pada tanggal 19/01/17, desa Sendangmulyo merupakan desa budaya. Menurut Setyawan Sahli yang dikutip dari RRI, kriteria desa budaya ada tiga, yaitu:

1. Kriteria dari sisi potensinya, ada apa saja dari kebudayaan itu.

2. Kriteria dari sisi ekspresi, potensi yang ada itu berapa kali diaktifkan, ada pelatihannya, ada latihannya, ada pentasnya.

3. Kriteria dari sisi konservasinya, keguyuban dan partisipasi masyarakat serta peran pemerintah desa dalam mengalokasikan dananya.

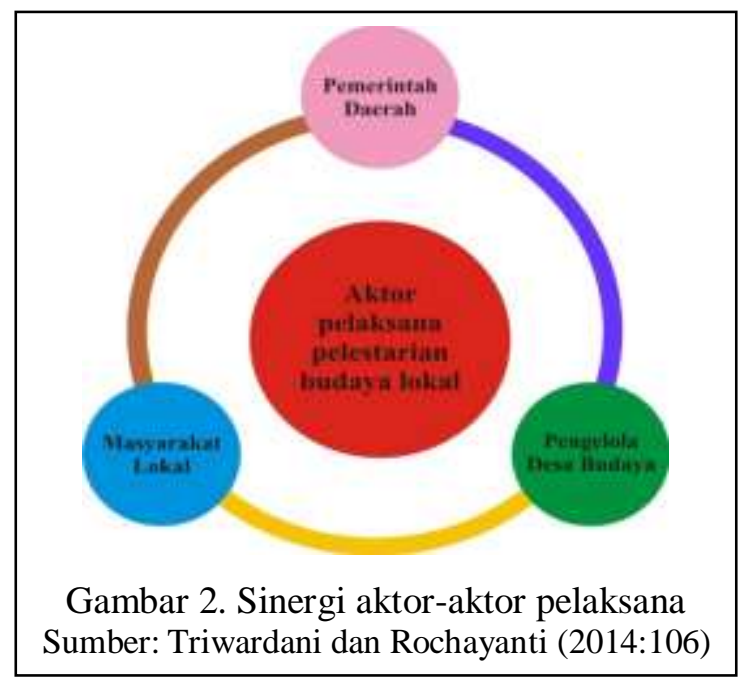


Desa yang telah ditetapkan menjadi desa budaya akan mendapatkan pendampingan dari dinas Kebudayaan DIY. 56 Desa yang sudah resmi menjadi desa
Budaya sesuai Surat Keputusan Gubernur DIY No 262/KEP/2016 tentang Penetapan Desa/ Kelurahan Budaya dapat dilihat dalam tabel berikut ini:

Tabel Desa Budaya di DIY

\begin{tabular}{|c|c|c|c|}
\hline NO & DESA BUDAYA & KECAMATAN & KABUPATEN \\
\hline 1 & Sinduharjo & Ngaglik & Sleman \\
\hline 2 & Bangunkerto & Turi & Sleman \\
\hline 3 & Sendangmulyo & Minggir & Sleman \\
\hline 4 & Argomulyo & Cangkringan & Sleman \\
\hline 5 & Wedomartani & Ngemplak & Sleman \\
\hline 6 & Banyurejo & Tempel & Sleman \\
\hline 7 & Wonokerto & Turi & Sleman \\
\hline 8 & Margodadi & Seyegan & Sleman \\
\hline 9 & Pendowoharjo & Sleman & Sleman \\
\hline 10 & Sendangagung & Minggir & Sleman \\
\hline 11 & Girikerto & Turi & Sleman \\
\hline 12 & Margoagung & Seyegan & Sleman \\
\hline 13 & Selopamioro & Imogiri & Bantul \\
\hline 14 & Sitimulyo & Piyungan & Bantul \\
\hline 15 & Sabdodadi & Bantul & Bantul \\
\hline 16 & Gilangharjo & Pandak & Bantul \\
\hline 17 & Bangunjiwo & Kasihan & Bantul \\
\hline 18 & Panggungharjo & Sewon & Bantul \\
\hline 19 & Mulyodadi & Bambanglipuro & Bantul \\
\hline 20 & Trimurti & Srandakan & Bantul \\
\hline 21 & Srigading & Sanden & Bantul \\
\hline 22 & Dlingo & Dlingo & Bantul \\
\hline 23 & Triwidadi & Pajangan & Bantul \\
\hline 24 & Seloharjo & Pundong & Bantul \\
\hline 25 & Pagerharjo & Samigaluh & Kulonprogo \\
\hline 26 & Tanjungharjo & Nanggulan & Kulonprogo \\
\hline 27 & Banjarharjo & Kalibawang & Kulonprogo \\
\hline 28 & $\begin{array}{r}-4 \\
\end{array}$ & Lendah & Kulonprogo \\
\hline 29 & Sukoreno & Sentolo & Kulonprogo \\
\hline 30 & $-x_{-1}$ & Temon & Kulonprogo \\
\hline 31 & Sendang sari & Pengasih & Kulonprogo \\
\hline 32 & Jatimulyo & Girimulyo & Kulonprogo \\
\hline 33 & Brosot & Galur & Kulonprogo \\
\hline 34 & Hargomulyo & Kokap & Kulonprogo \\
\hline 35 & Bugel & Panjatan & Kulonprogo \\
\hline 36 & Tuksono & Sentolo & Kulonprogo \\
\hline 37 & Sogan & Wates & Kulonprogo \\
\hline 38 & Tayuban & Panjatan & Kulonprogo \\
\hline 39 & Kalirejo & Kokap & Kulonprogo \\
\hline 40 & Semin & Semin & Gunungkidul \\
\hline 41 & Semanu & Semanu & Gunungkidul \\
\hline 42 & Bejiharjo & Karangmojo & Gunungkidul \\
\hline 43 & Kemadang & Tanjungsari & Gunungkidul \\
\hline
\end{tabular}




\begin{tabular}{|l|l|l|l|}
\hline NO & \multicolumn{1}{|c|}{ DESA BUDAYA } & \multicolumn{1}{c|}{ KECAMATAN } & \multicolumn{1}{c|}{ KABUPATEN } \\
\hline 44 & Putat & Patuk & Gunungkidul \\
\hline 45 & Girisekar & Panggang & Gunungkidul \\
\hline 46 & Giring & Paliyan & Gunungkidul \\
\hline 47 & Katongan & Nglipar & Gunungkidul \\
\hline 48 & Kepek & Wonosari & Gunungkidul \\
\hline 49 & Jerukwudel & Girisubo & Gunungkidul \\
\hline 50 & Tambakromo & Ponjong & Gunungkidul \\
\hline 51 & Wiladeg & Karangmojo & Gunungkidul \\
\hline 52 & Beji & Ngawen & Gunungkidul \\
\hline 53 & Ngalang & Gedangsari & Gunungkidul \\
\hline 54 & Giripurwo & Purwosari & Gunungkidul \\
\hline 55 & Kricak & Tegalrejo & Kota Yogyakarta \\
\hline 56 & Terban & Gondokusuman & Kota Yogyakarta \\
\hline
\end{tabular}

Sumber : Dinas Kebudayaan Propinsi DIY (2016)

\section{Potensi Desa Sendangmulyo}

Desa Sendangmulyo

memenuhi kriteria desa budaya, yaitu memiliki potensi budaya dari masing-masing dusun yang setiap tahun dipentaskan dalam gelar budaya di desa Sendangmulyo. Potensi Budaya yang dimiliki Desa Sendangmulyo antara lain:

\section{Tabuh Gamelan}

Desa Sendangmulyo memiliki Sumber Daya Manusia yang berpotensi tabuh gamelan. Pada awalnya yang mempunyai potensi tabuh gamelan ini hanya beberapa orang saja dengan peralatan yang kurang lengkap. Adanya potensi tabuh gamelan ini dikembangkan dalam seni karawitan dengan diperolehnya hibah seperangkat gamelan perunggu dari dinas kebudayaan propinsi DIY pada tahun 2017. Karawitan mengacu pada musik gamelan yang bersistem nada non diatonis (dalam laras slendro dan pelog) yang garapangarapannya menggunakan sistem notasi, warna suara, ritme, memiliki fungsi, pathet dan aturan yang tampak dalam sajian gendhing, baik yang berbentuk sajian instrumental dan vokal yang mengandung nilai-nilai historis dan filosofis. Perangkat gamelan yang digunakan dalam seni karawitan memiliki dua laras yaitu laras slendro dan pelog.

a. Laras Slendro

Laras Slendro adalah sistem urutan nada-nada yang terdiri dari lima nada dalam satu gembyang dengan pola jarak yang hampir sama rata. Nada yang digunakan dalam laras slendro adalah:

1) Penunggul (barang) diberi simbol 1 , dibaca siji atau ji.

2) Gulu atau Jangga, diberi simbol 2, dibaca loro atau disingkat ro.

3) Dhodho (Jaja atau tengah), diberi simbol 3, dibaca telu atau lu.

4) Lima, diberi simbul 5, dibaca limo disingkat 5.

5) Nem, diberi simbol 6, dibaca nem.

Selain lima nada nada pokok tersebut juga sering disebut beberapa laras seperti:

6) Barang, yaitu nada gembyangan dari penunggul, diberi simbol 1 dengan titik di atas angka, dibaca ji atau siji.

7) Manis, yaitu nada gembyangan gulu, diberi simbol angka 2 dengan titik di atas (manis hanya digunakan untuk laras kenong dan kempul). 


\section{b. Laras Pelog}

Gendhing yang disajikan dalam laras pelog sering hanya menggunakan lima nada saja, terutama dalam penyajian gendhing pelog hasil alih laras slendro dimana gendhing yang aslinya disajikan dalam laras slendro, kemudian disajikan dalam laras pelog. Dalam karawitan jawa, gendhing dapat dan boleh disajikan dalam laras yang berbeda.

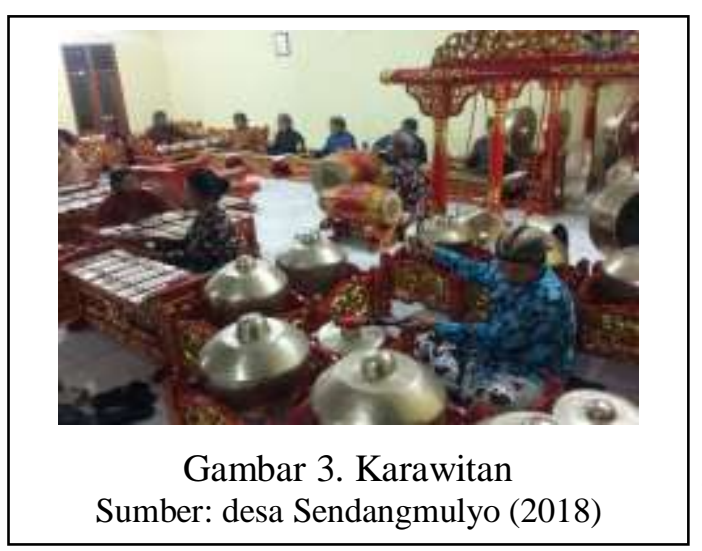

\section{Seni Tari}

Seni tari merupakan ungkapan jiwa yang mengandung unsur keindahan dalam bentuk gerakan yang teratur sesuai dengan irama yang mengiringinya. Unsur utama dalam tari yaitu wiraga (fisik), wirama (iringan musik), dan wirasa (penjiwaan atau ekspresi). Tari memiliki beberapa fungsi, yaitu :

a. Tari sebagai alat pemersatu bangsa. Pagelaran festival tari nasional daerah dapat menjadi alat pemersatu bangsa. Melalui festival tari tersebut, masingmasing peserta dapat saling berbagi dan belajar serta memperkenalkan tarian daerahnya.

b. Tari sebagai media ekspresi. Tari dapat menciptakan rangkaian gerak yang dapat membuat penikmatnya tertarik terhadap sesuatu yang ada dan terjadi di sekitarnya. c. Tari sebagai sarana upacara. Tari dapat digunakan dalam upacara keagamaan, upacara kebesaran keistanaan, dan upacara dalam kehidupan manusia seperti panen.

d. Tari sebagai media komunikasi. Tari menyampaikan pesan yang ada dalam setiap gerakannya untuk mengucapkan selamat datang kepada tamu.

e. Tari sebagai media berfikir kreatif. Tari sebagai salah satu seni dapat menjadi alat untuk berfikir kreatif dalam hal logika, bahasa, visual, kinestik, musik, intrapersonal dan interpersonal.

f. Tari sebagai media pengembangan bakat. Seni tari bisa menjadi alat untuk mengembangkan bakat bagi pecinta seni tari.

g. Tari sebagai hiburan. Tari sebagai hiburan harus bervariasi agar tidak membosankan. Kostum dan tata panggungnya harus dipersiapkan dengan cara yang menarik.

h. Tari sebagai media pergaulan. Kegiatan tari seperti latihan dan pementasan bersama adalah sarana pergaulan yang baik.

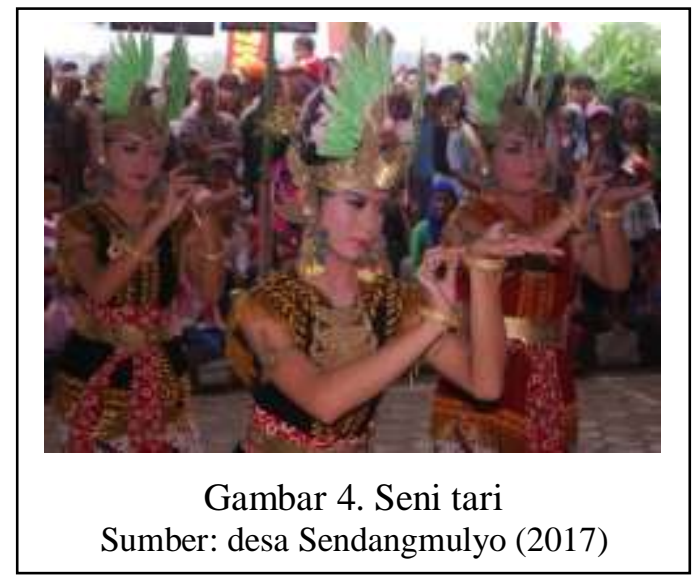


3. Jathilan dan Encling

Tari Jathilan merupakan tari berpasangan yang ditarikan oleh 2 orang penari. Adapun Makna Bentuk Simbolik Tari Jathilan adalah sebagai berikut:

a. Dari segi gerak tari Jathilan adalah ungkapan jiwa keprajuritan. Keprajuritan yang dimaksud berlatih perang di atas kuda.

b. Dari segi busana tari Jathilan adalah menggambarkan pakaian seorang prajurit. terdiri dari warna hitam, merah, putih dan kuning. Hal ini mengandung arti dan karakteristik sendiri-sendiri yaitu:

1) Warna hitam melambangkan sifat berwibawa, tenang dan berisi.

2) Warna merah berarti berani sesuai dengan karakter yang heroic (terbuka dan terus terang).

3) Warna putih berarti keberanian yang dilandasi dengan tujuan suci.

4) Warna kuning berarti mempunyai cita-cita untuk memperoleh kebahagian dan kejayaan.

c. Dari segi properti yang digunakan penari jathilan adalah jaran, yang dikenakan penari sebagai alat bantu waktu menari.

d. Dari segi tata rias, tari Jathilan menggambarkan simbolisasi seorang prajurit yang gagah dan pemberani, hal tersebut nampak pada alis dan godheg.

e. Dari segi iringan, tari Jathilan dalam gendhing sampak menggambarkan simbolisasi jiwa kesatria yang tangguh dan unggul, dalam gendhing obyog menggambarkan simbolisasi jiwa prajurit yang halus, lembut dan lemah gemulai, gendhing panaragan menggambarkan simbolisasi jiwa prajurit yang berani. Jadi, Tari Jathilan adalah penggambaran seorang prajurit yang halus dan lemah lembut, namun memiliki jiwa yang kuat, tangguh, dan percaya diri.

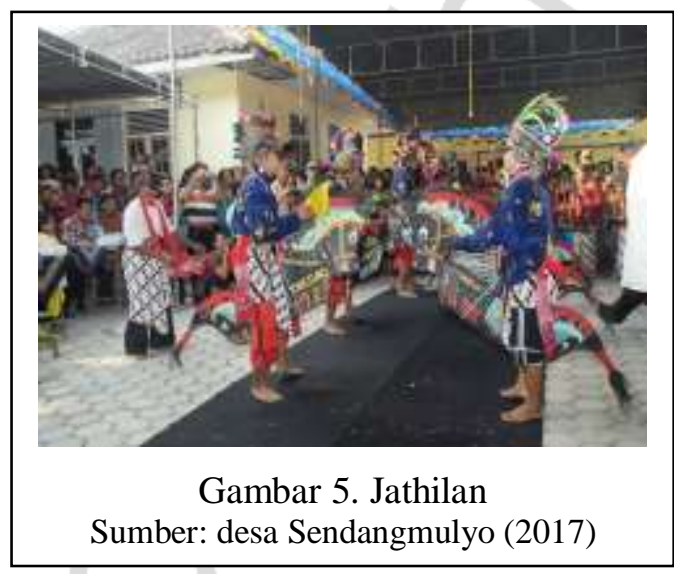

4. Thek-thek

Thek-thek merupakan sebuah kesenian tradisional dengan menggunakan kentongan sebagai alat musik. Kenthongan sebagai seni Thek-thek menjadi seni musik dengan ritme yang sangat indah. Pemain kesenaian ini mengenakan busana tradisional sehingga baik alat musik maupun kostum yang digunakan benarbenar memperlihatkan budaya lokal.

\section{Gejog lesung}

Gejog lesung dimainkan oleh ibu-ibu. Gejog lesung oleh masyarakat jaman dahulu digunakan sebagai alat untuk memisahkan padi dari kulitnya. Padi yang sudah kering dimasukkan dalam lesung kemudian ditumbuk dengan alu sehingga menimbulkan irama. Seiring perkembangan jaman saat ini untuk menghasilkan beras petani tidak perlu menumbuk padi karena sudah ada alat penggiling padi. Dengan kreatifitas yang tinggi, gejok lesung ini dilestarikan menjadi kesenian tradisional di desa Sendangmulyo. 


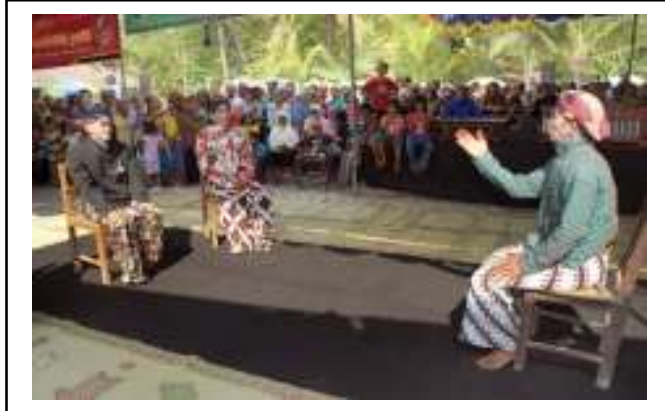

Gambar 6. Kethoprak

Sumber: desa Sendangmulyo (2017)

\section{Kubro Siswo}

Kubro siswo merupakan kesenian tradisional yang berlatarbelakang penyebaran islam. Kata Kubro berarti besar dan siswo berarti siswa atau murid. Sehingga kubro siswo dapat diartikan sebagai murid Tuhan yang diimplementasikan dalam pertunjukan yang selalu menjunjung kebesaran nama Tuhan.

\section{Kethoprak Wijoyo Mulyo}

Kethoprak Wijoyo Mulyo adalah paguyuban kethoprak desa Sendangmulyo. Pemain-pemain kethoprak ini adalah warga masyarakat di desa Sendangmulyo yang terdiri dari warga masyarakat di berbagai padukuhan wilayah desa Sendangmulyo.

\section{Kerajinan}

Masyarakat Desa Sendangmulyo mayoritas mempunyai mata pencaharian sebagai pengrajin dari bahan dasar bambu. Banyaknya bambu yang tumbuh di wilayah desa Sendangmulyo membuat masyarakat mempunyai kreativitas menganyam bambu menjadi besek, tampah, tumbu, dan kerajinan bambu lainnya. Kendala yang dihadapi oleh pengrajin bambu ini adalah permodalan dan lemahnya sumber daya manusia bidang pemasaran. Pemasran penting bagi industry apapun untuk memperkenalkan pada pasar (pelanggan) yang tepat, waktu yang tepat dengan harga yang tepat melalui saluran yang tepat (Ali Hasan, 2015). Pemasaran yang dilakukan belum dapat dilakukan secara luas, masih sebatas dijual kepada pengepul.

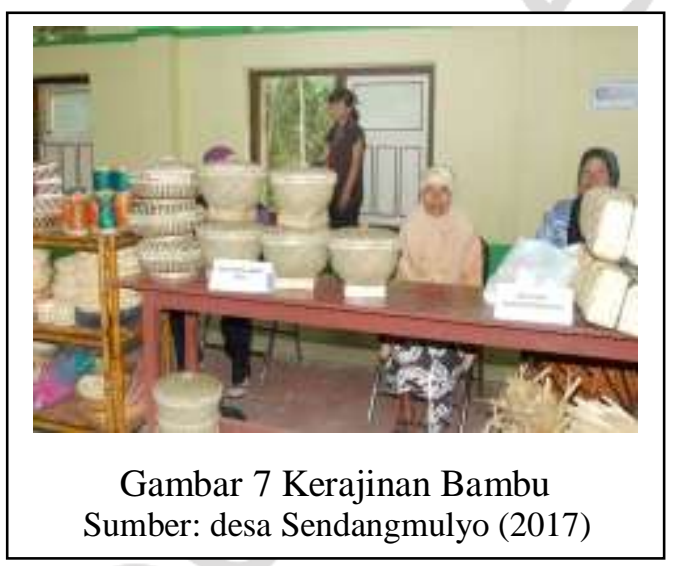

9. Kuliner Lokal

Kuliner lokal merupakan budaya unggulan di desa Sendangmulyo. Kuliner dari bahan dasar lokal seperti singkong, talas, pisang dan belut sering dihadirkan dalam pameran budaya di Kabupaten Sleman, Jogja Expo Center, desa Sendangmulyo dan sebagainya. Kurangnya inovasi juga membuat wirausaha yang bergerak bidang kerajinan dan kuliner ini mendapatkan pembinaan dari Kelompok Desa Perempuan Indonesia Maju Mandiri (Desa Prima) Sendangmulyo berupa pelatihan pengembangan produk dan kredit lunak.

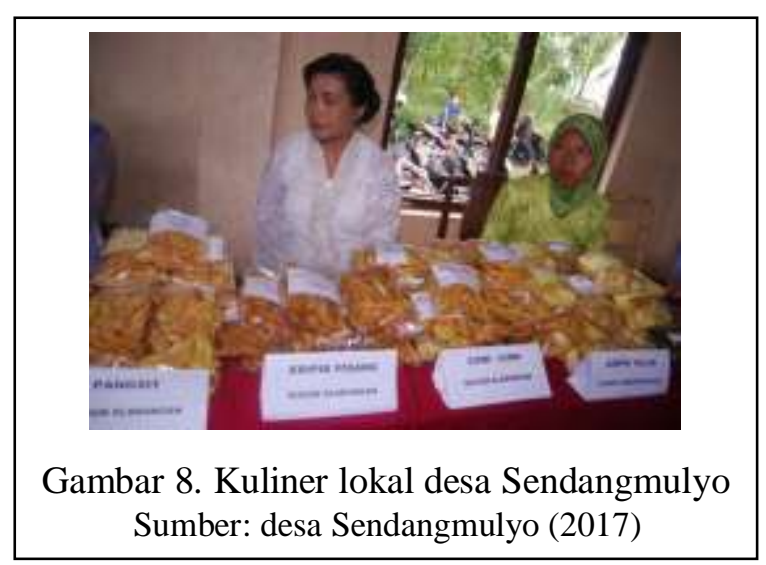


10. Merti Desa

Orang Jawa dalam kehidupan beragamannya masih diwarnai dengan "kejawen", sehingga mereka masih mencampur adukkan antara ajaran agama dengan upacara-upacara kejawen. Salah satu upacara keagamaan yang dilakukan orang Jawa ada yang dinamakan dengan slametan yang dipimpin oleh kaum. Menurut orang Jawa, arwah orang-orang tua sebagai nenek moyang yang telah meninggal dunia berkeliaran sekitar tempat tinggalnya, atau sebagai arwah leluhur menetap di makam. Mereka masih mempunyai hubungan dengan keluarga yang masih hidup sehingga suatu saat arwah itu datang ke kediaman anak keturunan. Roh-roh yang baik yaitu roh nenekmoyang atau kerabat disebut dhanyang, mbahu rekso, atau sing ngemong. Dhanyang ini dipandang sebagai roh yang menjaga dan mengawasi seluruh masyarakat desa. Dari sinilah kemudian timbul upacara bersih desa. Upacara Merti Desa pada hakekatnya merupakan upacara bersih desa yang merupakan tradisi warisan leluhur.

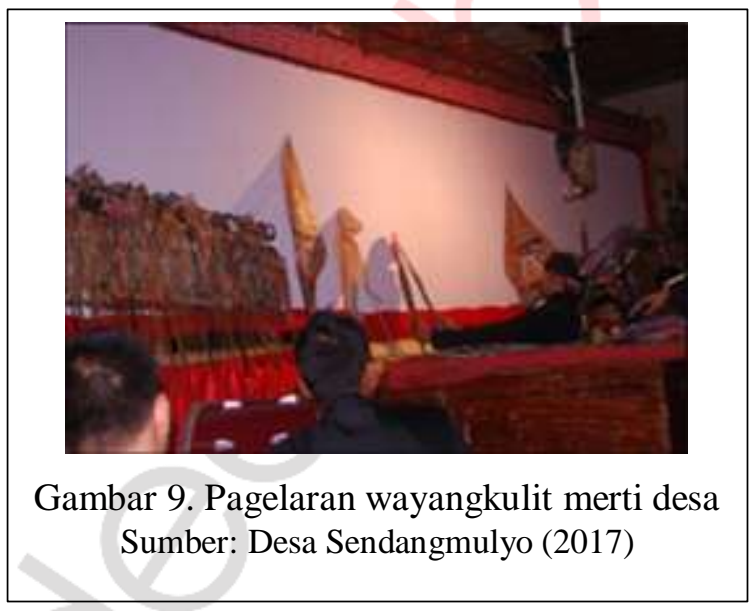

\section{Pembahasan}

Implementasi kebijakan desa budaya berdasarkan penilaian Dinas Kebudayaan
DIY, Sendangmulyo berada pada kategori desa budaya maju yaitu memiliki banyak potensi budaya, kegiatan pelatihan dan pelestarian budaya dilakukan secara rutin, dan partisipasi masyarakat sangat tinggi dengan terlibat langsung dalam pentas seni dan pameran budaya. Analisis SWOT desa Sendangmulyo dapat dilihat dalam tabel berikut ini:

\section{Tabel Analisis SWOT Desa Sendangmulyo}

\begin{tabular}{|l|l|}
\hline $\begin{array}{l}\text { Kekuatan: } \\
\text { Potensi budaya } \\
\text { Dukungan dari } \\
\text { masyarakat }\end{array}$ & $\begin{array}{l}\text { Kelemahan } \\
\text { SDM yang kurang terampil } \\
\text { Kelembagaan yang kurang } \\
\text { memahami fungsinya } \\
\text { Sarana yang kurang memadai }\end{array}$ \\
\hline $\begin{array}{l}\text { Peluang: } \\
\begin{array}{l}\text { Menjadi } \\
\text { destinasi } \\
\text { budaya }\end{array}\end{array}$ & $\begin{array}{l}\text { Ancaman: } \\
\text { Pemahaman budaya dan } \\
\text { keterlibatan generasi muda } \\
\text { masih kurang }\end{array}$ \\
\hline
\end{tabular}

Sumber: desa Sendangmulyo (2017)

Dalam mengatasi kelemahan SDM, kelembagaan serta sarana dan prasarana di desa Sendangmulyo, pemerintah desa didukung oleh Dinas Pariwisata DIY serta partisipasi dari masyarakat melakukan beberapa kebijakan. Kebijakan dan peran serta dari Dinas Kebudayaan, desa Sendangmulyo, masyarakat lokal dan aktor pelaksana budaya yaitu:

1. Dinas Kebudayaan meningkatkan sarana dan prasarana dengan:

a. Memberikan bantuan dana untuk pelaksanaan kegiatan pelestarian budaya.

b. Pada Tahun 2017 Dinas Kebudayaan DIY memberikan hibah berupa seperangkat gamelan perunggu kepada Desa Sendangmulyo.

2. Desa Sendangmulyo meningkatkan lembaga pengelola desa melalui peningkatan manajemen dengan:

a. Pembinaan kepada kelompokkelompok sadar budaya. 
b. Mengadakan gelar budaya untuk menampilkan budaya budaya yang dimiliki masing-masing padukuhan.

c. Mengadakan lomba antar padukuhan untuk meningkatkan rasa persatuan dan persaudaraan dalam melestarikan budaya lokal.

d. Mengelola makanan yang menjadi ciri khas serta memperhatikan higiene dan sanitasi.

e. Membuat pelatihan yang berkaitan dengan psikologi pelayanan akomodasi, pelayanan makanan dan minuman, serta courtesy dalam menghadapi tamu.

f. Merumuskan strategi promosi dan pemasaran yang efektif dan efisien.

g. Memberikan pembekalan kepada masyarakat tentang pengetahuan Cross Culture (pengetahuan silang budaya).

h. Merancang program promosi yang efektif.

i. Bekerjasama dengan Balai Latihan Kerja (BLK), Desa Prima, Perguruan Tinggi, pemerintah dan swasta dalam mengadakan pelatihan maupun pembinaan untuk mengembangkan potensi yang dimiliki desa Sendangmulyo.

3. Masyarakat lokal berperan aktif dalam kegiatan pelatihan, dan pementasan seni budaya serta menjunjung tinggi nilai-nilai budaya desa Sendangmulyo.

4. Aktor pelaksana pelestari budaya meningkatkan motivasi, pengetahuan dan partisipasi masyarakat melalui:

a. Revitalisasi budaya, agar budaya lokal dapat diserap oleh generasi muda.

b. Melakukan studi banding dan pelatihan dengan desa lain yang telah mengembangkan desa wisata dan budayanya.

c. Pelatihan-pelatihan budaya kepada generasi muda supaya budaya lokal tidak punah.

d. Menjunjung tinggi nilai-nilai budaya lokal dan ketahanan budaya melalui pembinaan kepada masyarakat.

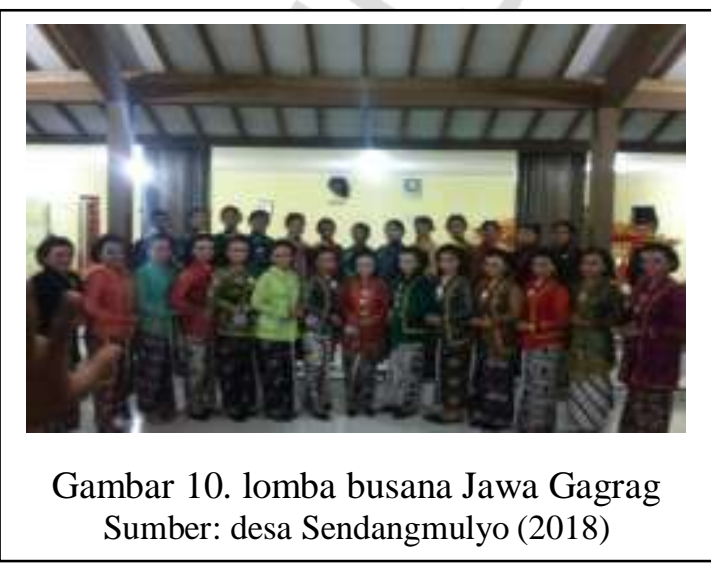

\section{KESIMPULAN DAN REKOMENDASI}

\section{Kesimpulan}

1. Potensi desa Sendangmulyo antara lain, Tabuh gamelan, Seni tari, Jathilan dan Encling, Thek-thek, Gejog lesung, Kubro siswo, Kethoprak, Kerajinan, Kuliner lokal, Merti desa

2. Implementasi kebijakan desa budaya ber dasarkan penilaian Dinas Kebudayaan DIY, Sendangmulyo berada pada kategori desa budaya maju. Kekuatan, kelemahan serta peluang dan ancaman desa Sendangmulyo adalah sebagai berikut:

a. Kekuatan: (1) Memiliki potensi budaya, 2) Adanya dukungan dari masyarakat

b. Kelemahan; (1) SDM yang kurang trampil, (2) Kelembagaan yang kurang memahami fungsinya. dan (3) Sarana yang kurang memadai. 
c. Peluang:Menjadi destinasi budaya.

d. Ancaman:Pemahaman budaya dan keterlibatan generasi muda masih kurang.

Dalam mengatasi kelemahan SDM, Kelembagaan serta sarana dan Prasarana di desa Sendangmulyo, Pemerintah desa dengan dukungan dari Dinas Kebudayaan Propinsi DIY melakukan kebijakan:

a. Meningkatkan motivasi pengetahuan dan partisipasi masyarakat melalui pelatihan-pelatihan.

b. Meningkatkan lembaga pengelola desa melalui peningkatan manajeman.

c. Meningkatkan sarana pendukung desa budaya dan memberikan pendanaan untuk mengadakan gelar budaya.

\section{Rekomendasi}

1. Tokoh masyarakat desa agar bersama sama menyatukan konsep, visi dan misi dalam menyusun perencanaan pengembangan Desa Budaya Sendangmulyo.

2. Pemerintah Kabupaten melalui Dinas Kebudayaan agar dapat memberi bantuan teknis maupun kemudahankemudahan.

3. Para pelaku wisata agar membantu memasarkan produk wisata dan budaya di Desa Sendangmulyo.

4. Para akademisi dapat membantu membuat kemasan ragam produk wisata dan budaya, pelatihan terhadap pengelola, membantu promosi dan pemasarannya.

\section{REFERENSI}

Hasan, Ali, 2015. Tourism Marketing. Yogyakarta: Center for Academic Publishing Service.
M.RRI.co.id/Yogyakarta//post/berita/35136 4/seni_budaya/56_desa_di_diy_me mperoleh_sk_gubernur_sebagai_des a_budaya_html.diakses pada tanggal 28 Februari 2018.

Mubah. A. Safril. 2011. Strategi meningkatkan Daya Tahan Budaya Lokal Dalam Menghadapi Arus Globalisasi. Departemen Hubungan Internasional, FISIP, Universitas Airlangga, Surabaya. Volume 24, No 4 hal : 302-308.

Nurdin dan usman. 2002. Konteks Implementasi Berbasis Kurikulum. Bandung. CV Sinar Baru.

Peraturan Menteri Pendidikan dan kebudayaan Republik Indonesia Nomor 10 tahun 2014) Tentang Pedoman Pelestarian Tradisi.

Peursen. 2009. Strategi Kebudayaan. Yogyakarta : Kanisius.

Surat Keputusan Gubernur DIY No 262/KEP/2016 tentang Penetapan Desa/Kelurahan Budaya

Sutrisno, Mudji. 2009. Ranah- Ranah Kebudayaan. Yogyakarta : Kanisius

Tahir, Arifin. 2014. Kebijakan Publik dan Transparansi Penyelenggaraan Pemerintah Daerah. Alfabeta: Bandung.

Triwardani, Reny dan Rochayanti. 2014. Implementasi Kebijakan desa Budaya dalam Upaya Pelestarian Budaya Lokal. Jurnal Unitri Vol 4 No 2.Universitas Pembangunan Nasional Veteran Yogyakarta. 